\title{
Tetralogy of Fallot with an Anomalous Coronary Artery: Current Surgical Perspective
}

\author{
MD. MAZIBUR RAHMAN \\ Department of Cardiac Surgery, Ibrahim Cardiac Hospital \& Research Institute(ICHRI), Dhaka. \\ Address of Correspondence: Dr. Md. Mazibur Rahman, Associate Professor and Consultant, Department of Cardiac Surgery, \\ Ibrahim Cardiac Hospital \& Research Institute(ICHRI), Dhaka, E-mail:drmuzib2009@yahoo.com
}

\begin{abstract}
:
The choice of the surgical technique and quality of surgical repair determine the cardiac outcome of Tetralogy of Fallot(TOF) with anomalous coronary artery(ACA). On the other hand, the type of surgical reconstruction depends on the size of pulmonary annulus and the exact location of ACA in relation to pulmonary annulus.A unified repair strategy that limits and balance between postoperative residual pulmonary stenosis(PS) and pulmonary insufficiency (PI) after patch enlargement is critical for preservation of ventricular function with or without deliberate sacrifice of ACA In condition of inadvertent transaction or necessiate sacrefice of ACA during right ventricular outflow tract obstruction (RVOTO) repair needs urgent coronary artery bypass grafting (CABG) using left internal mamary artery(LIMA)/autologous venous conduit to prevent myocardial infarction. Palliative procedure in neonates is needed in conditions eg., anomalous coronaries, multiple ventricular septal defects(VSD), generalized critical illness, rehabilitation of small or distorted pulmonary artery (PA), prematurity and low birth weight etc.is followed by repair.
\end{abstract}

Keywords: Tetralogy of Fallot, Anomalous coronary artery, Right ventricular outflow tract obstruction, Left internal mamary artery, Trans-annular patch.

\section{Introduction:}

Tetralogy of Fallot (TOF) is the earliest ever known cyanotic lesion to be described and was among the first congenital cardiac abnormalities to be repaired successfully by Lillehei et al. about 60 years ago. ${ }^{1}$ There has been tremendous changes in the surgical treatment of congenital heart disease (CHD) in the past 3 decades in favour of early primary repair for the vast majority of cardiac malformations. Repair of TOF has been at the forefront of this transformation. ${ }^{2}$ Encouraged by this favourable experience, the approach of early primary repair has also been extended to more complex lesions with excellent results. This approach has been motivated by the desirability of establishing normal anatomic and physiologic conditions as early in life as possible, to avoid the undesirable long term effects of unrepaired CHD, as well as to avoid the complications of palliative operations and the risk of multiple operations. ${ }^{3,4}$

TOF is an important lesion for pediatric and congenital cardiac surgeons having the options of initial palliative and definitive cardiac operations. Congenital coronary anomalies are a recognized cause of myocardial ischaemia and sudden cardiac death, especially among children and young adults. ${ }^{5}$ The prevalence of congenital coronary anomalies has been estimated at approximately 0.85\%-1\% of general population and the anomalous coronary
arteries(ACA) are associated with Tetralogy of Fallot with reported incidence of 2-10\%. ${ }^{5-9}$ TOF is often lethal if untreated, it now has a good prognosis with timely surgical intervention.

In the past, the presence of a prominent coronary artery crossing the RVOT has traditionally been considered to be a contraindication to primary repair in infancy, often led to initial palliation with Modified Blalock-Taussig shunt (MBTS)/ Central shunt etc. ${ }^{2}$ Surgical approach in patients having one coronary artery crossing the obstructed and hypertrophied right ventricular outflow tract (RVOT) is challenging and associated with increased operative mortality and morbidity. ${ }^{7}$ Presurgical coronary artery documentation is essential through echocardiography, coronary angiography(CAG), CT angiogram or recently developed electrocardiography-gated multidetector row CT (MDCT)- a noninvasive, accurately imaging technique to visualize the coronary arteries from their origin, course and termination and is superior to conventional coronary angiogram for the most appropriate surgical technique ${ }^{10}$ Various techniques have been described to establish the continuity between the right ventricle and the pulmonary artery. The type of surgical reconstruction is individualized depending on both the anatomy of the RVOT and the course of the coronary artery over it.

The best age for TOF repair remains controversial but the ideal repair should be suitable for children of all ages but 
can be repaired at any age safely with low operative risk, even with complex heart surgery in infants

\section{Discussion:}

Over the ensuing years, with the advent of increased experience, modification of surgical techniques, changes in myocardial protection, refinement of anaesthesiologic and better postoperative care have reduced operative mortality to an acceptable level among the cyanotic newborns and infants. The surgical strategy has been dominated worldwide by the technique initially described, the trans-right ventricular approach. In 1963, an alternate strategy for repairing combining trans-atrial(TA) and transpulmonary(TP) approaches has been described by Hudspeth and colleagues. ${ }^{11}$ This technique has since been favoured by some centres giving the functional benefits include a lower incidence of arrhythmia and lower incidence and severity of early and late postoperative dysfunction of RV. ${ }^{12,13}$

Recently the ability to repair TOF early in life, regardless of anatomy of the coronary artery has largely been the reason for many academic centers to no longer perform routine coronary artery angiography prior to surgery and is still controversial. It is no doubt, an ideal situation to have a pre-operative delineation of the coronary arteries including large conal branches in all patients. Their delineation is mandatory in the following situations: ${ }^{8}$ (i)for intraoperative choice of surgical technique and optimal timing of surgery (ii) Previous intrapericardial surgery where the coronary artery anatomy is not obvious because of adhesions. (iii) In infants, where total correction may be deferred to a later date when the option of a conduit repair is available. (iv)If the LAD is too small or absent in its normal location then great care should be exercised during intracardiac repair (ICR).But this abnormality is important surgically for the sake of infundibular resection, where a subpulmonic incision is usually made during a surgical repair because the anomalous LAD courses subepicardially or remains buried in the myocardium across the RVOT. ${ }^{14}$

Congenital anomalous origin of the coronary arteries has been implicated in chest pain, sudden death, cardiomyopathy, syncope, dyspnea, ventricular fibrillation and myocardial infarction. ${ }^{15}$ In TOF, an anomalous origin of a major coronary artery across the RVOT is important surgically because a subpulmonic incision is usually made during a surgical repair. So identification of an anomalously arising major coronary artery is an indispensable part of preoperative workup for patients with TOF to prevent accidental injury or transection inadvertently (resulting in serious myocardial ischaemia and death) during attempts to enlarge RVOT. ${ }^{6,7}$ The immediate and long-term outlook depends on the adequate and sustained relief of RVOTO without injury to the coronary artery supplying the significant portion of myocardium. The ACA crossing the RVOT presents a unique problem among the patients with TOF and hypoplastic pulmonary annulus because it cannot be enlarged with the standard technique using a trans-annular patch. Several techniques have been advocated for circumventing this situation for achieving total correction. ${ }^{16,17}$ Usually repair through the RA, RV and pulmonary artery(PA) ie., TA or a combination of TATP repair is possible only when the pulmonary annulus is considered adequate. ${ }^{17}$ Surgical treatment continues to evolve for annular hypoplasia associated with anomalous coronary vessel.16 When significant degrees of hypoplasia of pulmonary valve annulus and the MPA is frequently encountered, the most preferred surgical option in such a situation is placement of a conduit interposition between RV and MPA for RVOT reconstruction through different techniques like oblique ventriculotomy, tailored ventriculotomy, Double barrel technique(two patch repair), pulmonary artery turn back technique, pulmonary homograft conduit, prosthetic conduit ${ }^{17}$ or even primary repair can be done without the use of a conduit by the translocation of MPA on the RVOT ${ }^{18}$ or transannular repair below a mobilized anomalous coronary artery ${ }^{19}$ or a new technique called "V-plasty"20 where reconstruction of RVOTO for enlargement of the anterior leaflet and pulmonary annulus with TAP while preserving its coaption surface which will grow up with patients age and will preserve native valve coaption in only mild to moderate annular- valvular stenosis.

However, the lack of availability and expensiveness and logistics of setting up of the homograft bank for the cryopreserved homograft's continue to encourage the nonconduit reconstructions of the right ventricular outflow tracts. It unfortunately do not grow and almost always calcify. ${ }^{21}$ Xenografts though offer off- the- shelf privileges, continue to be expensive. Additionally there is always the risk of subjecting the patient to many re-operations. Moreover, the short-term and the long-term results of the hetero-homografts are not much different. ${ }^{22}$ Schichter et al have demonstrated in their 15 year follow-up study of fresh autologous pericardial conduits with an excellent short and long-term outcome and may not require any reoperations because the size of the conduit(16 mm and more). ${ }^{23}$ The technique considered to be the best that offers the advantage of one final surgery for the patient by PA annuloplasty with the insertion of autologous 
pericardial patch containing a monocusp and avoids the cost of conduits during the total corrections, thereby offering financial relief for the patients in the part of the world where public funding for cardiac surgery continues to be very low.

A hypoplastic pulmonary annulus with a normal coronary arterial pattern needs a trans-annular vertical incision followed by a patchplasty is the most preferred approach. $^{24}$ But the surgical technique in presence of ACA across the RVOT will depend on the location, the level and tortuosity of the anomalous coronary artery and the length, size of the MPA, annular diameter and severity of RVOTO. ${ }^{7,16}$ If the PV annulus is normal/near normal size, obviating the need for transannular patch, the relief of RVOTO is accomplished through TA \pm TP or even infundibulotomy may be done without any injury to the anomalous coronary artery. When the PV annulus is hypoplastic, necessitating a trans-annular patch, ${ }^{16}$ the presence of an ACA across the site of intended reconstruction necessitated the use of one of following several techniques to avoid a conduit. (i) When in close proximity $<10 \mathrm{~mm}$ of the ACA and the hypoplastic pulmonary valve ring preclude a TA-TP repair, ${ }^{25}$ but necessitates the use of either MPA translocation to RV or pulmonary artery turn back technique provided the pulmonary artery is long and not grossly hypoplastic. If it is not longer enough then alternative ways is double Barrel technique with the incorporation of autologous pericardium can be done after tailored or transverse ventriculotomy. (ii)When an ACA is tortuous, located at a distance of $>10 \mathrm{~mm}$. from pulmonary valve (PV) annulus then RV-PA communication can be done by transannular repair under a mobilized ACA and placement of a TAP without stretching and compression of ACA by the distended RV which is not uncommon during the immediate postoperative period or by utilization of pulmonary homograft conduit. (iii) when the MPA become shorter and narrower, annulus being hypoplastic with an ACA away from the annulus across the RVOT. Then it would not be possible to maintain RV-PA continuity through either a pulmonary homograft conduit or translocation of MPA to RV but an extracardiac pulmonary conduit (prosthetic) replacement may be an alternative method in such a situation. However, the probability of re-operation for conduit replacement and the risk for ischemia due to compression of the coronary artery by the conduit are major disadvantages of this technique. ${ }^{7}$ In such a situation, the best way is to do transpulmonary, transannular, and transventricular pericardial patchplasty with the incorporation of a autologous pericardial monocusp valve at pulmonary artery after valvotomy. In case of mild to moderate pulmonary annular hypoplasia, a recent novel technique called "V-plasty"20 having the advantage of preserving the native valvular coaption surface which will grow up with the patient's age without the development of PI or PS and do not require any isolated monocusp insertion. Several surgical strategies have been used to protect the ACA. Bonchek in 1976 described the method of dissecting the coronary artery off the outflow tract with placement of an outflow patch beneath the artery. ${ }^{19}$ This technique carries the risk of stretching with resultant ischemia caused by right ventricular dilatation, which is not uncommon immediately after the operation. Although Tchervenkov et al. ${ }^{16}$ reported successful mobilization of the coronary arteries in children, this seems to be more securely used in adult patients due to the possibility of spasm of the coronary artery in children. Meyer et al. did transverse ventriculotomy below the LAD for relief of infundibular stenosis and closure of the ventricular septal defect. ${ }^{9}$ It carries a risk for arrhythmia, RV dysfunction and sudden death. Hurwitz and coworkers recommended a separate pulmonary artery incision for relief of pulmonary stenosis and enlargement with a patch if necessary. ${ }^{6}$ Humes and coworkers suggested using either patch reconstruction or conduit placement in this situation depending on the exact location and tortuosity of the anomalous artery and the level and severity of the right ventricular outflow tract obstruction. ${ }^{7}$ The transatrial approach may be useful in the presence of this anomaly. ${ }^{26}$ However, its effectiveness and usefulness are limited if the obstruction is primarily infundibular and the pulmonary valve annulus is of adequate size for body weight and surface area.

Below the ACA lies the RV body which is dangerous for ventriculotomy for a conduit to maintain RV-PA continuity. It is better to avoid venticulotomy into the RV body and limited it to the outlet portion of RV ie., infundibulum which has a relatively minor functional contribution to RV stroke volume. It has become evident that early post operative low cardiac output syndrome (LCOS), arrythmia, RV dysfunction and a risk of sudden death are all related in part to the RV body incision. ${ }^{27} \mathrm{TA}$ approach may be used, particularly when a ventriculotomy is dangerous due to unfavourable coronary anatomy, or when the RVOTO is discrete and low. After closure of the VSD and resection of the infundibular septo-parietal fibromuscular bands, a pericardial patch is placed on the right ventricular outflow tract to enlarge it. Inappropriate relief of RVOTO either by over or undersized TAP during elective annular enlargement is like a double edge sword causing either 
free pulmonary insuffficiency(PI) or pulmonary stenosis(PS). Free PI inturn has been causally linked to an array of abnormalities complicating the immediate postoperative course as well as adversely affecting the long term outlook, including RV dysfunction, poor functional status, arrythmias and even sudden death. ${ }^{28,29}$ On the other hand, avoidance of TAP at the cost of leaving behind residual stenosis is also considered undesirable and has been found to be detrimental to the extent of causing arrhythmia or resulting in reoperations. ${ }^{29}$ When dealing with a narrowed pulmonary annulus, the feasibility of TA repair is best judged preoperatively by calculating the Z-scores on angiocardiography. The traditional criteria suggests that patients with $\mathrm{z}$-scores of $<-2$ are likely to require a TAP. ${ }^{27}$ However, there have been reports of TA repair being successfully performed in patients with z-scores of as low as -3 and even $-4 .{ }^{27}$ Similarly as regards the post repair peak pressure in RV compared to the left ventricle (pRV/LV), for some workers 0.8 represents the acceptable upper limit, ${ }^{30}$ where as others opine that a value of even upto 1.0 can be safely accepted to offer a valve sparing repair. ${ }^{31}$ But $0.5-0.65$ is directly linked to the quality of surgical repair. For those using a Rowlatts table for intraoperative decision making for a flaccid arrested heart, it has been conventional to select a Hegar's dilator equal to or $2 \mathrm{~mm}$ more than appropriate for the given weight of the patient ${ }^{32}$ but there are no reports of repair being done while accepting a lower Hegar size.

During extension of the pulmonary arteriotomy across the annulus to the infundibulum to repair the hypoplastic annulus, the ACA might be inadvertently injured or transected. Then bypass grafting is the only method of restoring blood supply distal to the transected vessel. Bhutany AK. ${ }^{14}$ is the first to report the use of LIMA graft directly to the distal segment of divided anomalous LAD. Berry and McGoon were the first to report aorta-coronary bypass grafting with autologous saphenous vein in $1973 .{ }^{8}$ Shaffer, Berman, and Waldhausen reported another case of saphenous vein grafting for divided anomalous LAD in a 13-year-old boy. ${ }^{26}$ Although di Carlo and colleagues reported aorta-coronary bypass with a polytetraflouroethylene (PTFE) graft in a 17-month-old boy, the graft was for a transected left coronary artery. ${ }^{33}$ On the basis of various reports of use of the LIMA for coronary artery disease, the use of a LIMA graft directly to the distal segment of divided ACA might do well for the patients where the ACA is inadvertently transected or needed deliberately secrefice. Postoperative electric ischaemic injury independently increases the risk of long term heart failure.
It has become evident that myocardial injury, coronary injury, right ventricular dysfunction, and arrhythmias are all related in part to RV-tomy, especially in the context of transannular patching and free pulmonary insufficiency (PI). In some patients, therefore, the late outcome will be compromised. Today we have a better understanding of some of the events leading to late right ventricular failure, and perhaps the technical ability to improve the results for the next generation of children undergoing repair, which constitutes the subject of this topic. Following TOF repair, there is almost always residual RVOTO, seen immediately or over time. Furthermore, the degree of RVOTO may be inversely proportional to the grade of PI. The traditional thinking regarding post repair TOF physiology has emphasized two points. The first is that postoperative RVOTO is undesirable, to the point that many surgeons would consider the setting of a RV / LV pressure ratio $<0.65$. The second traditional belief is that postoperative PI is well tolerated and that only very significant RV dilation is problematic. Both concepts have been challenged in recent years. PI is exacerbated by loss of distal compliance and lessened or prevented by proximal resistance. Free PI causes right ventricular dilation that in turn compresses the LV. The degree of PI depends in part on pulmonary arterial compliance, and the location of resistance relative to valveless RV-PA junction. ${ }^{34}$ The functional reserve and myocardial contractility of the right (and possibly left) ventricle decrease with chronic PI, ${ }^{35}$ Such physiology is well tolerated in the majority of patients for a prolonged period of time, but some will eventually experience decreased exercise tolerance and progressive RV dilation and failure. ${ }^{36}$ This in turn predisposes the patient to late life-threatening ventricular arrhythmias and sudden death. ${ }^{36}$. Stenosis, even mild, is detrimental to ventricular function while insufficiency is well tolerated. Pulmonary stenosis(PS), in addition to insufficiency, seemed to have been beneficial by promoting hypertrophy, limiting RV dilatation, and enhancing myocardial contractility. But the goal of treatment should have a balance between PS and PI

The acute change from a pressure-loaded to a volumeloaded RV, in addition to the right ventriculotomy, can adversely affect the performance of the RV in the immediate postoperative period. ${ }^{37}$ The postoperative TOF physiology leads us directly to the TA-TP tetralogy repair as a possible solution. The TA-TP approach involves RVOT reconstruction via the tricuspid valve (TV) and PV, and VSD closure via TV. ${ }^{38}$ Usually the repair is completed without division of the annulus, although if this is not possible, limited ventriculotomy is done, which is reconstructed with a TAP. A large ventriculotomy into the 
RV body is usually avoided, limiting it to the outlet portion of RV or infundibulum, which has a relatively minor functional contribution to RV stroke volume ${ }^{39}$.

\section{Palliation for TOF:}

In the past, the presence of a prominent coronary artery crossing the RVOT, multiple VSDs, neonates with an unacceptable level of hemoglobin saturation and/or hypercyanotic spells, generalized critical illness, rehabilitation of small or distorted PAs, prematurity and low birth weight has traditionally been considered to be a contraindication to primary repair in infancy ${ }^{2}$ often led to initial palliation with Modified Blalock-Taussig shunt (MBTS)/ Central shunt etc. This is mostly because of the operative morbidity and mortality, ${ }^{7}$ during complete cardiac repair when one need to enlarge the $\mathrm{RVOT}^{7,8}$ and because of the possibility of injury to the ACA across an stenotic and hypoplastic RVOT. Another argument in favour of a palliative approach in infancy has been the desire to avoid the placement of a small conduit in a baby. The argument is often put forth as primary neonatal repair versus palliative systemic to pulmonary arterial shunt with later repair. Although there is documented morbidity and interval mortality with this approach there are centers that report excellent outcome and a risk of palliation that approaches $0 \%{ }^{3,38} \mathrm{CHD}$ in Newborns are known to be susceptible to abnormal brain development and widespread CNS abnormalities, which may be exacerbated following neonatal operations utilizing cardiopulmonary bypass(CPB), especially with deep hypothermiacirculatory arrest (DHCA). Newborns are known to be more susceptible to brain injury such as periventricular leukomalacia in the perioperative period, especially with the use of DHCA. ${ }^{40}$ Therefore, if neonatal tetralogy surgery can be safely delayed, and if other outcome variables would look similar with an operation at 3-6 months of age (with or without a MBTS), then one should follow a strategy of elective non-neonatal primary repair. Palliation achieves the goal of ameliorating cyanosis and encouraging pulmonary arterial growth.

\section{Timing of surgery:}

TOF is often lethal if untreated, it now has a good prognosis with timely surgical intervention. Proponents for primary neonatal repair cite factors such as prevention of time related end organ damage from cyanosis, removal of stimulus for RV hypertrophy and fibrosis, improved lung development (vascular and alveolar), avoidance of deleterious effects and risks of palliative shunts and psychosocial -economic issues. The best age for TOF repair remains controversial. TOF can be repaired at any age with a low operative risk in units equipped to deal safely with complex heart surgery in infants. The TA-TP strategy particularly is easier and more reliable in infants 2 - 6 months of age than in neonates, but is certainly possible at any age. Many surgeons employing a neonatal tetralogy repair strategy still employ a transventricular approach, with a transannular valveless RVOT patch reconstruction, despite the now well documented effects of these strategies on the RV.

Cyanotic CHD in newborns are known to be more susceptible to brain injury(periventricular leukomalacia) during perioperative period from CPB with or without DHCA. ${ }^{40}$ This is generally not occurs in non-neonatal repair. Therefore, if neonatal tetralogy surgery can be safely delayed, and if other outcome variables would look similar with an operation at 3-6 months of age (with or without a MBTS), then an elective non-neonatal primary repair can be done easily. Non-neonatal primary elective repair (3-6 months) is preferable to a staged procedure involving palliative shunts in most patients. Cyanotic neonates who are suitable anatomic and physiologic candidates will also have a primary repair. In practice, most patients will undergo elective repair by 3-4 months of age, or sooner if indicated clinically. The shunt strategy is reserved for selected cases with unfavorable outcome.

The argument is often put forth as primary neonatal repair versus palliative systemic to pulmonary arterial shunt with later repair. Therefore even the strongest proponents of neonatal primary repair still consider the MBTS, a requirement for selected cases, such as anomalous coronaries, multiple VSDs, generalized critical illness, rehabilitation of small or distorted PAs, prematurity and low birth weight, need to establish a volume load to prevent diastolic dysfunction after repair (older children). In fact, $75 \%$ of tetralogy patients do not require any surgical treatment in the neonatal period. The important argument therefore is not "primary repair vs shunt" but "neonatal vs non-neonatal” elective primary repair”.

\section{Use of monocusp valve:}

Several surgeons have described strategies to limit the size of the right ventriculotomy and reduce the incidence of PI. Valved homografts and xenografts were proposed as the most anatomic and physiologic way to resolve RVOT obstruction, but all will eventually need replacement because of patient growth and conduit deterioration. ${ }^{41}$ The use of a monocusp valve created from pericardium, xenograft valve cusps, fascia lata, autologous pulmonary 
artery wall, or PTFE has been shown to decrease shortterm PI. ${ }^{3}$ The augmentation with autologous pericardium is simple, does not significantly prolong the operation, reduces the degree of PI and protect against RV failure in the immediate postoperative period, and improves the early outcome after TA-TP repair requiring a TAP alone. Monocusp insertion is easily accomplished and is inexpensive. The monocusp thus appears to have all of the advantages of a valved conduit but without the late obstruction leading to reoperation. However, the monocusp has limited durability. ${ }^{41}$ Many groups have abandoned the monocusp because they did not think that it provided a significant advantage for the long term.

\section{Conclusion:}

In the modern era, the immediate outcome of TOF repair is good employing diverse surgical strategies based on the improved understanding of post repair physiology but the goal of treatment should include the balance between PS and PI, avoidance of long term complications like residual RVOTO, RV hypertrophy, heart failure, a low probability of early and late reoperations and reduction of mortality. A good neurodevelopmental and functional status and quality of life could complete the expectations. There are important implications for timing, technique of surgery and continued evolution is expected.

\section{References:}

1. Lillehei CW, Varco RL, Cohen M, Warden HE, Gott VL, DeWall RA, et al.The first open hear corrections of tetralogy of Fallot: A 26-31 year follow-up of 106 patients.Ann Surg. 1986; 204:490-502.

2. Castaneda AR, Jonas AR, Mayer JE Jr,Hanley FL. Tetralogy of Fallot. In: Castaneda AR, Jonas AR, Mayer JE Jr,Hanley FL, editors. Cardiac surgery of neonate and infant. Philadelphia:WB Saunders;1994.p.222.

3. Gladman G, McCrindle BW, Williams WG, Freedom RM, Benson LN.The modified Blalock- Taussig shunt: Clinical impact and morbidity in Fallot's tetralogy in the current era. J Thorac Cardiovasc Surg. 1997;114:25-30

4. Van Son JAM. Repair of tetralogy of Fallot with anomalous origin of lef anterior descending coronary artery. J Thorac Cardiovasc Surg. 1995;110:561-562

5. Cheitlin MD, De Castro MD, McAllister HA: Sudden death as a complication of anomalous left coronary origin from the anterior sinus of valsalva ; a not so minor congenital anomaly. Circulation 1974; 50:780-87

6. Hurwitz RA, Smith W, King H, Girod DA, Caldwell RL. Tetralogy of Fallo with abnormal coronary artery: 1967 to 1977. J Thorac Cardiovasc Surg1980; 80:129 34.

7. Humes RA, Driscoll DJ, Danielson GK, Puga FJ. Tetralogy of Fallot with anomalous origin of left anterior descending coronary artery. Surgical options. J Thorac Cardiovasc Surg 1987; 94: 794-7

8. Berry BE, McGoon DC. Total correction for tetralogy of Fallot with anomalous coronary artery Surgery 1973;74: 894-89

9. Meyer J, Chiariello L, Hallman GL, et al. Coronary artery anomalies in patients with tetralogy of Fallot. J Thorac Cardiovasc Surg 1975; 69:373-6

10. Kim SY.Seo JB, DoDH,Heo JN, Lee JS, Song JW et al.:Classification and MDCT.Radiographics 2006; 26: 317-34

11. Hudspeth AS, Cordell AR, Johnston FR. Transatrial approach to total correction of tetralogy of Fallot Circulation 1963;27:796-800.

12. Atallah-Yunes NH, Kavey RE, Bove EL, Smith FC, Kveselis DA, Byrum CJ, et al. Postoperative assessment of a modified surgical approach to repair of tetralogy of Fallot: long-term follow-up. Circulation. 1996;94(9 suppl):II22-II26

13. Norgård G, Gatzoulis M, Moraes F, Lincoln C, Shore DF, Shinebourne EA, et al. Relationship between type of outflow tract repair and postoperative right ventricular diastolic physiology in tetralogy of Fallot. Circulation. 1996;94: 3276-3280

14. Bhutany AK, Koppala MM, Abraham KA, Balakrishnan KR Desai RN.Inadvertent transaction of anomalous arising LAD during Tetralogy of Fallot repair, bypass grafted LIMA . J Thorac Cardiovasc Surg1994; 08:589-90

15. Angelini P, Velasco JA, Flamm S. Coronary anomalies: incidence , pathophysiology and clinical relevance.Ciirculation.2002;105: 2449-54.

16. Tchervenkov CI, Pelletier MP,Shum-Tim D, Beland MJ,Rohlicek C Primary repair minimizing the use of conduits in neonates and infants with tetralogy or double-outlet right ventricle and anomalous coronary arteries. J Thorac Cardiovasc Surg 2000;119: 314-

17. Brizard CP, Mas C, Sohn YS, Cochrane AD, Karl TR. Trans atrial Transpulmonary Tetralogy of Fallot repair is effective in the presence ofanomalous coronary arteries.J Thorac Cardiovascular Surg 1998; 119: 314-23

18. Lecompte Y,Neveux JY, Leca F, et al. Reconstruction of the pulmonary outflow tract without prosthetic conduit.J Thorac Cardiovasc Surg 1982;84:727-33

19. Bonchek LI. A method of outflow tract reconstruction in tetralogy of Fallot with anomalous anterior descending coronary artery. Ann Thorac Surg 1976; 21:451-3.

20. Ustunsoy H, Gokaslan G, Ozcaliskan O et al.”V-plasty”: a novel technique to reconstruct Pulmonary valvular and annular stenosis in patients with right ventricular outflow tract obstruction. Journal of Cardiothoracic Surgery 2o13;8: 55- 59.

21. Kumar RK, Srivastava S. Pediatric Heart Care in India, In press, Heart

22. Powell AJ, Lock JE, Keane JF, Perry SB. Prolongation of conduit life span by percutaneous stent implantation. Intermediate results. Circulation 1995; 92:3282-8. 
23. Schichter AJ, Kreutzer C, Mayorquim RC, Simon JL, Roman MI, Vasquez $\mathrm{H}$ et al. Five to fifteen year follow-up of fresh autologus pericardial valved conduits. J Thorac Cardiovasc Surg 2000;119: 869-79.

24. Hallman GL, Cooley DA. Surgical treatment of tetralogy of Fallot: experience with indirect techniques. J Thorac Cardiovasc Surg 1963; 46:419-23

25. O’Blenes SB, Freedman RM, Coles JG. Tetralogy of Fallot with anomalous LAD: Repair without conduit. Ann Thorac Surg 1996; 62:1186-88

26. Shaffer CW, Berman W, Waldhausen JA. Repair of divided anomalous anterior descending coronary artery in tetralogy of Fallot. Ann Thorac Surg 1979; 27: 250

27. Airan B, Chaudhary SK,Kumar HVJ et al . Total transatrial correction of TOF: No outflow patch technic . Ann Thorac Surg 2006;82: 1316-21

28. Gatzoulis MA, Balaji S, Webber SA, et al. Risk factors for arrhythmia and sudden cardiac death late after repair of tetralogy of Fallot multicentre study. Lancet 2000;356:975981

29. Kirklin JW, Blackstone EH, Jonas RA, et al. Morphologic and surgical determinants of outcome events after repair of tetralogy of Fallot and pulmonary stenosis: a two-institution study. J Thorac Cardiovasc Surg. 1992;103:706-23.

30. Naito Y, Fujita T, Manabe H, Kawashima Y. The criteria for reconstruction of the right ventricular outflow tract in total correction of tetralogy of Fallot J Thorac Cardiovasc Surg 1980;80:574-581

31. Kaushal SK, Radhakrishanan S, Dagar KS, et al. Significant intraoperative right ventricular outflow gradients after repair for tetralogy of Fallot: to revise or not to revise? Ann Thorac Surg. 1999;68:1705-13.

32. Lev M, Rimoldi HJA, Rowlatt UF. The quantitative anatomy of cyanotic Tetralogy of Fallot. Circulation. 1964;30:531-8.
33. Di Carlo D, De Nardo D, Ballerini L, Marcelletti C. Injury to the left coronary artery during repair of tetralogy of Fallot: successful aorta-coronary polytetrafluoroethylene graft. J Thorac Cardiovasc Surg 1987;93: 468

34. Kilner PJ, Balossino R, Dubini G, Babu-Narayan SV, Taylor AM, Pennati G, et al. Pulmonary regurgitation: The effects of varying pulmonary artery compliance, and of increased resistance proximal or distal to the compliance. Int J Cardiol. 2008 Aug 20;

35. Hon J, Steendijk P, Khan H, Wong K, Yacoub M. Acute effects of pulmonary artery banding in sheep on right ventricle pressure-volume relations: Relevance to the arterial switch operation. Acta Physiol Scand. 2001;172:97-106

36. Leeuwenburgh B, Helbing W, Steendijk P, Schoof P,Baan J. Biventricular systolic function in young lambs subject to chronic systemic right ventricular pressure overload. Am J Physiol Heart Circ Physiol. 2001:281:2697-704.

37. Gundry SR, Razzouk AJ,Boskind JF, Bansal R, Bailey LL. Fate of the pericardial monocusp pulmonary valve for right ventricular outflow tract reconstruction: Early function, late failure without obstruction. J Thorac Cardiovasc Surg. 1994;107:908-12. [

38. Karl TR, Sano S, Pornviliwan S, Mee RB. Tetralogy of Fallot: Favorable outcome of non-neonatal transatrial, transpulmonary repair. Ann Thorac Surg. 1992;54:903-7.

39. Geva T, Powell AJ, Crawford EC, Chung T, Colan SD. Evaluation of regional differences in right ventricular systolic function by acoustic quantification echocardiography and cine magnetic resonance imaging.Circulation. 1998;98:339-45.

40. Licht DJ, Wang J, Silvestre DW, Nicolson SC, Montenegro LM, Wernovsky G,et al. Preoperative cerebral blood flow is diminished in neonates severe congenital heart defects. Thorac Cardiovasc Surg. 2004;128:841

41. Sano S,Karl TR, Mee RB. Extracardiac valved conduits in the pulmonary circuit. Ann Thorac Surg. 1991;52:285-90. 